\title{
BMJ Open Complaint risk among mental health practitioners compared with physical health practitioners: a retrospective cohort study of complaints to health regulators in Australia
}

\author{
Benjamin G Veness (D) , ${ }^{1}$ Holly Tibble (D) , ${ }^{2}$ Brin FS Grenyer (D) ,3,4 \\ Jennifer M Morris, ${ }^{2}$ Matthew J Spittal (D) ,2 Louise Nash, ${ }^{5,6}$ David M Studdert, ${ }^{7,8}$ \\ Marie M Bismark (D) ${ }^{2}$
}

To cite: Veness BG, Tibble $\mathrm{H}$, Grenyer BFS, et al. Complaint risk among mental health practitioners compared with physical health practitioners: a retrospective cohort study of complaints to health regulators in Australia. BMJ Open 2019;9:e030525. doi:10.1136/ bmjopen-2019-030525

- Prepublication history and additional material for this paper are available online. To view these files, please visit the journal online (http://dx.doi. org/10.1136/bmjopen-2019030525).

Received 18 March 2019 Revised 15 November 2019 Accepted 15 November 2019

Check for updates

(C) Author(s) (or their employer(s)) 2019. Re-use permitted under CC BY-NC. No commercial re-use. See rights and permissions. Published by BMJ.

For numbered affiliations see end of article.

Correspondence to

Dr Benjamin G Veness;

bven5712@uni.sydney.edu.au

\section{ABSTRACT}

Objectives To understand complaint risk among mental health practitioners compared with physical health practitioners.

Design Retrospective cohort study, using incidence rate ratios (IRRs) to analyse complaint risk and a multivariate regression model to identify predictors of complaints.

Setting National study using complaints data from health regulators in Australia.

Participants All psychiatrists and psychologists ('mental health practitioners') and all physicians, optometrists, physiotherapists, osteopaths and chiropractors ('physical health practitioners') registered to practice in Australia between 2011 and 2016.

Outcome measures Incidence rates, source and nature of complaints to regulators.

Results In total, 7903 complaints were lodged with regulators over the 6 -year period. Most complaints were lodged by patients and their families. Mental health practitioners had a complaint rate that was more than twice that of physical health practitioners (complaints per 1000 practice years: psychiatrists 119.1 vs physicians $48.0, p<0.001$; psychologists 21.9 vs other allied health $7.5, p<0.001)$. Their risk of complaints was especially high in relation to reports, records, confidentiality, interpersonal behaviour, sexual boundary breaches and the mental health of the practitioner. Among mental health practitioners, male practitioners (psychiatrists IRR: 1.61, $95 \% \mathrm{Cl} 1.39$ to 1.85 ; psychologists IRR: $1.85,95 \% \mathrm{Cl}$ 1.65 to 2.07 ) and older practitioners ( $\geq 65$ years compared with $36-45$ years: psychiatrists IRR $2.37,95 \% \mathrm{Cl} 1.95$ to 2.89; psychologists IRR $1.78,95 \% \mathrm{Cl} 1.47$ to 2.14 ) were at increased risk of complaints.

Conclusions Mental health practitioners were more likely to be the subject of complaints than physical health practitioners. Areas of increased risk are related to professional ethics, communication skills and the health of mental health practitioners themselves. Further research could usefully explore whether addressing these risk factors through training, professional development and practitioner health initiatives may reduce the risk of complaints about mental health practitioners.
Strengths and limitations of this study

- We examined complaints to health regulators about all registered mental health practitioners, compared with a comparison group of physical health practitioners, in a national jurisdiction over a multiyear period.

- The availability of high-quality denominator data (the national register of health practitioners) facilitated more sophisticated identification and analysis of risk clusters than any previous study of complaints about mental health practitioners in Australia or internationally.

- Our study covered a broader set of complaint types than most previous studies, including concerns about clinical performance, professional conduct and health impairment.

- We were unable to measure a number of important practitioner-level variables such as whether the psychiatrists and psychologists in our study were working in public or private practice, or the complexity of their caseload.

- The complaints in our study probably underrepresent harm and concern experienced by patients as we only included complaints to regulators, thus missing complaints made directly to the practitioner, their employer or other agencies, and adverse events where no complaint was laid.

\section{INTRODUCTION}

Relative to other health professionals, psychiatrists and psychologists have been shown to have high rates of complaints and disciplinary actions. ${ }^{1-5}$ Prominent issues include sexual boundary violations, ${ }^{6-14}$ concerns about practitioners' involvement in legal proceedings or reports, ${ }^{11}{ }^{15-17}$ and breaches of confidentiality. $^{917}$

However, existing studies have significant limitations. Common methodological 
limitations include lack of a comparison group, high potential for confounding among identified risk factors and no adjustment for time spent engaged in clinical care (ie, exposure time). Among studies that have used comparison groups to assess medicolegal risk, the comparison has been between psychiatrists and doctors in other medical specialties. ${ }^{1-35} 18$ Almost all previous studies focus on psychiatrists and psychologists in the USA, which has a highly litigious and expensive medicolegal environment. By comparison, other jurisdictions such as Australia, the UK and New Zealand offer patients more accessible and affordable options for redress. To the best of our knowledge, no previous research has analysed the complaint risk of psychiatrists and psychologists (collectively referred to herein as 'mental health practitioners') compared with practitioners who primarily treat physical health ('physical health practitioners').

The distinction between these two types of practitioners is somewhat artificial because there is no bright line between mental and physical health. Many psychiatrists and psychologists treat patients with complex physical health conditions, and many other medical specialists and allied health practitioners treat patients with mental illness. Nevertheless, we hypothesised that differences in patterns of complaints between practitioners grouped in this way would be detectable and informative for practitioners, health service managers, regulators and patient advocates as a way of targeting and prioritising efforts to improve the delivery of mental healthcare. An increasing body of research demonstrates an association between complaints by patients and peers, and adverse events or other poor outcomes of clinical care. ${ }^{19-22}$ Complaints can provide information on patient safety and experience that may not emerge through other sources of data such as incident reports and malpractice claims. In turn, thoughtful analysis of complaints can inform service improvements. ${ }^{23} 24$

We used a national dataset of formal complaints about the conduct, performance and health of registered health practitioners in Australia. Our study had three aims. First, we sought to characterise the frequency, source, outcome and nature of complaints about mental health practitioners compared with physical health practitioners. Second, we aimed to identify specific complaint issues for which mental health practitioners were at higher risk than physical health practitioners. Third, we sought to identify the characteristics of mental health practitioners who are at increased risk of complaints. We expected to find higher rates of complaint about mental health practitioners compared with physical health practitioners, especially in relation to issues of particular sensitivity or relevance to the provision of mental healthcare.

\section{METHODS}

Setting and data

The Australian Health Practitioner Regulation Agency (AHPRA) supports the 15 National Boards that are responsible for regulating the health professions in Australia. AHPRA maintains a national register of health practitioners. AHPRA also receives complaints and manages investigations into the professional conduct, performance or health of registered health practitioners, on behalf of the Boards, except in New South Wales where this is undertaken by the Health Professional Councils Authority and the Health Care Complaints Commission, and in Queensland where this may be undertaken by the Office of the Health Ombudsman (from July 2014 onwards).

Anyone may lodge a complaint about a health practitioner. In practice, most complaints are made by patients and their families. Complaints are assessed and, where appropriate, the practitioner is given the opportunity to respond. A profession-based board (eg, the Medical Board of Australia) can take action to protect the public if it considers that the health practitioner poses a risk to the public. A decision by the regulator to take no further action can occur when a complaint is not upheld (for example if there are evidentiary difficulties in substantiating a complaint), if the concerns have already been adequately addressed by the practitioner or if there is no ongoing risk to the public.

We created a linked dataset using registration data and complaints data. The registration dataset consisted of information on health practitioners registered in Australia at any time between January 2011 and December 2016 (the 'study period'). The information included practitioners' age, sex, profession, specialty (if applicable), practice location and dates of registration. The complaints dataset consisted of information on all complaints about these practitioners lodged with regulators during the study period. AHPRA provided complaints data for all states and territories, except New South Wales. HPCA provided equivalent data for New South Wales. We linked the datasets using unique, anonymised identifiers.

The University of Melbourne's Health Sciences Human Ethics Sub-Committee approved the study (Ethics Application 1543670.5). AHPRA and HPCA provided the data in a de-identified form, under a strict data protection plan and deed of confidentiality.

\section{Practitioners of interest}

We defined the four profession groups of interest as follows: (1) psychiatrists, (2) psychologists, (3) physicians (defined as specialists in internal medicine, including paediatricians) and (4) other allied health practitioners (defined as optometrists, physiotherapists, osteopaths and chiropractors for the purposes of this study).

Physicians were chosen as the comparison group for psychiatrists because they undergo a similar period of training and work in similar healthcare settings. The choice of comparators for psychologists was more challenging because there is no obvious comparison group. We chose optometrists, physiotherapists, osteopaths and chiropractors. Like psychology, all four of these professions are members of the Allied Health Professions 
Australia and have been covered by the national health practitioner regulation scheme since its inception. In addition, the nature of professional practice in these four professions is similar to psychology in that they often involve one-on-one patient consultations, ongoing therapeutic relationships and private practice settings.

To control for differences in clinical hours worked by practitioners during the period they were under observation, we created a measure of exposure time ('practice years') and adjusted for this in our analyses (see the online supplementary file). Practice years were estimated at the practitioner level as a multiplicative function of two variables: the duration of registration and the average number of clinical hours worked per week by practitioners of the same age, sex and profession. ${ }^{25}$

AHPRA provided information on practitioners' birth dates in 5-year bands (eg, 1970 to 1974). We recoded these dates to reflect each practitioner's age group in 2015. Complaints were originally coded by case managers at AHPRA and HPCA into one of 149 complaint categories. Two reviewers (MB and JM) independently classified these 149 categories into 16 complaint issues (eg, sexual boundaries, prescribing and so on) using a methodology applied in earlier work. ${ }^{26}$ Any differences were resolved by consensus between the two reviewers and reviewed by a senior author (DS).

\section{Analysis}

We used counts and percentages to describe the characteristics of practitioners and complaints, including the reporting source, complaint issue and final outcome. Significant differences between professions for each characteristic were identified using $\chi^{2}$ tests. We calculated incidence rate ratios (IRRs) to quantify the complaint rate among psychiatrists (compared with physicians) and psychologists (compared with other allied health practitioners) after adjusting for practice years. Finally, we conducted a multivariate negative binomial regression analysis to estimate the association between age, sex, practice location and rate of complaints among mental health practitioners. All analyses were conducted using Stata V.14.0 (College Station, Texas, USA).

\section{Patient and public involvement}

JM, who contributed to the interpretation of results and the writing of the manuscript, is also a patient advocate. Much of the data analysed in this study came from complaints made by patients or their families about the healthcare they have received.

\section{RESULTS \\ Characteristics of practitioners}

From 2011 to 2016, a total of 3706 psychiatrists and 37201 psychologists were registered to practise in Australia, as were 8303 physicians and 64787 other allied health practitioners (table 1). These health professions differed from their counterparts with respect to age and sex $(p<0.001)$. Overall, psychiatrists were the oldest group, with one in five psychiatrists aged $\geq 65$ years. Although most psychiatrists and physicians were men $(62 \%$ and $71 \%$, respectively), over $70 \%$ of psychologists and other allied health practitioners were women ( $79 \%$ and $71 \%$, respectively).

\section{Source, outcome and nature of complaints}

Health regulators received 1944 complaints about psychiatrists and 2448 complaints about psychologists during the study period (table 2). Patients or their relatives

Table 1 Characteristics of practitioners

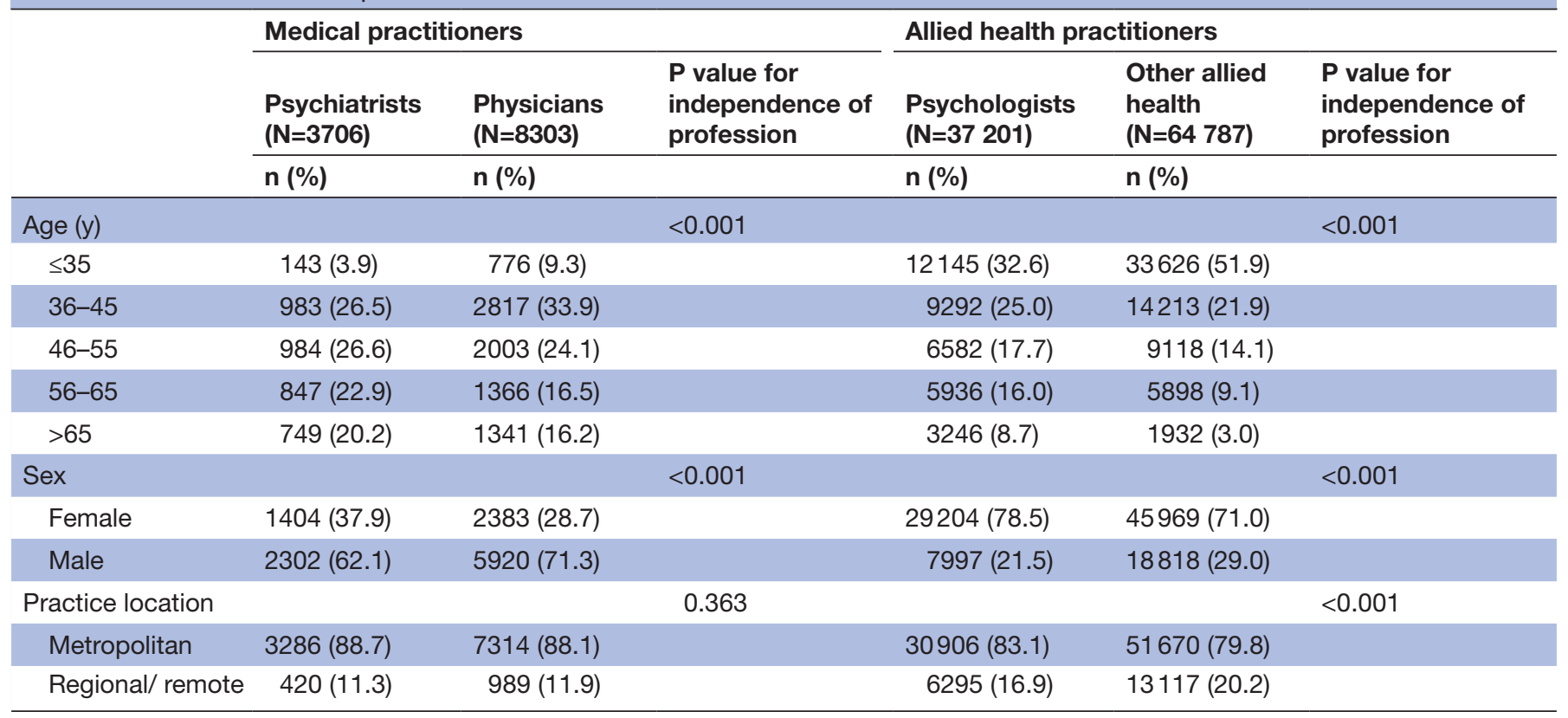

$\chi^{2}$ tests were used to calculate $p$ values. 
Table 2 Source, outcome and nature of complaints

Medical practitioners

Allied health practitioners

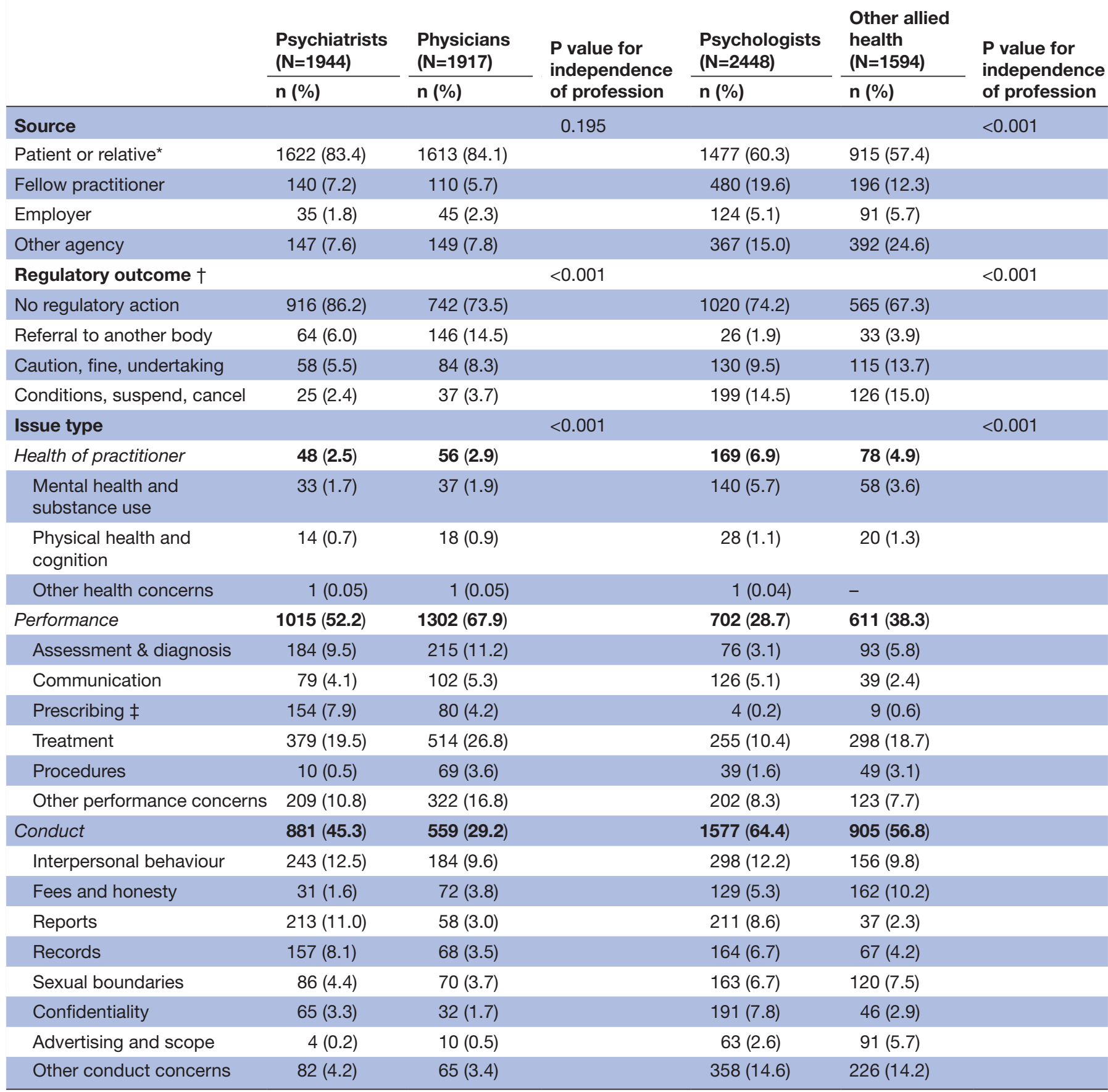

*Including complaints commissions.

†Excludes complaints that were still open at the end of the study period ( $n=118$ for psychiatrists, $n=118$ for physicians, $n=214$ for psychologists, $n=181$ for other allied health), a very small number of cases with an unknown outcome ( $n=1$ for physicians, $n=3$ for psychologists, $n=3$ for other allied health) and complaints from NSW where outcomes were not included in our dataset ( $n=763$ for psychiatrists, $n=789$ for physicians, $n=856$ for psychologists, $n=571$ for other allied health).

łIncludes unlawful use or supply of medications.

lodged the majority of these complaints $(83.4 \%$ for psychiatrists; $60.3 \%$ for psychologists). Physicians attracted 1917 complaints and other allied health practitioners attracted 1594 complaints.
Professional conduct issues accounted for a larger share of complaints about mental health practitioners, compared with physical health practitioners $(45.3 \%$ for psychiatrists compared with $29.2 \%$ for physicians; $64.4 \%$ 
for psychologists compared with $56.8 \%$ for other allied health practitioners). Alleged breaches of sexual boundaries accounted for $4.4 \%$ of complaints about psychiatrists (3.7\% of complaints about physicians) and $6.7 \%$ of complaints about psychologists $(7.5 \%$ of complaints about other allied health practitioners).

At the end of the study period, approximately $90 \%$ of the complaints had been closed. Only a minority of complaints resulted in formal regulatory action such as a caution, reprimand, conditions or suspension (7.8\% of complaints about psychiatrists, $12.0 \%$ about physicians, $23.9 \%$ about psychologists and 28.7\% about other allied health practitioners). Complaints about physical health practitioners were significantly more likely to result in formal regulatory action than those about their mental health practitioner counterparts $(\mathrm{p}<0.001)$. The rest of the complaints ended with referral to another agency or with no further regulatory action.

\section{Complaint rates and IRRs of complaint issues}

The complaint rate among psychiatrists was more than double than among physicians (119.1 vs 48.0 complaints per 1000 practice years, $\mathrm{p}<0.001)$. The complaint rate among psychologists was nearly treble than among other allied health practitioners (21.9 vs 7.5 complaints per 1000 practice years, $\mathrm{p}<0.001)$. This translates to approximately one complaint every 8 years of practice for psychiatrists, one every 21 years for physicians, one every 46 years for psychologists and once every 134 years for other allied health practitioners.

Mental health practitioners had significantly higher rates of complaints relating to certain issues (figure 1), including reports (psychiatrists vs physicians IRR 9.0, 95\% CI 6.7 to 12.2; psychologists vs other allied health practitioners IRR 10.9, 95\% CI 7.6 to 15.9), records (psychiatrists IRR 5.6, 95\% CI 4.2 to 7.6 ; psychologists IRR $4.7,95 \%$ CI 3.5 to 6.3 ), confidentiality (psychiatrists IRR 5.0, 95\% CI 3.2 to 7.8; psychologists IRR 7.9, 95\% CI 5.7 to 11.2 ), interpersonal behaviour (psychiatrists IRR 3.2, 95\% CI 2.7 to 3.9; psychologists IRR 3.6, 95\% CI 3.0 to 4.5 ) and sexual boundary breaches (psychiatrists IRR 3.0, 95\% CI 2.2 to 4.2 ; psychologists 2.6, 95\% CI 2.0 to 3.3). Although complaints about practitioners' own mental health were rare in absolute terms, they were more than twice as common among mental health practitioners (psychiatrists IRR 2.2, 95\% CI 1.3 to 3.6; psychologists IRR 4.6, 95\% CI 3.4 to 6.4 ).

Psychiatrists had nearly double the risk of complaints about communication (IRR 1.9, 95\% CI 1.4 to 2.6) and nearly five times the risk of complaints about prescribing as their physician colleagues (IRR 4.7, 95\% CI 3.6 to 6.3). On the other hand, psychiatrists were at a lower risk of complaints about procedures (IRR 0.4, 95\% CI 0.2 to 0.7). Psychologists also had a higher risk of complaints about communication than their counterparts (IRR 6.2, $95 \%$ CI 4.3 to 9.1 ).

\section{Multivariable predictors of complaints among mental health practitioners}

Given the increased risk of complaints that we observed among mental health practitioners as a group, our final

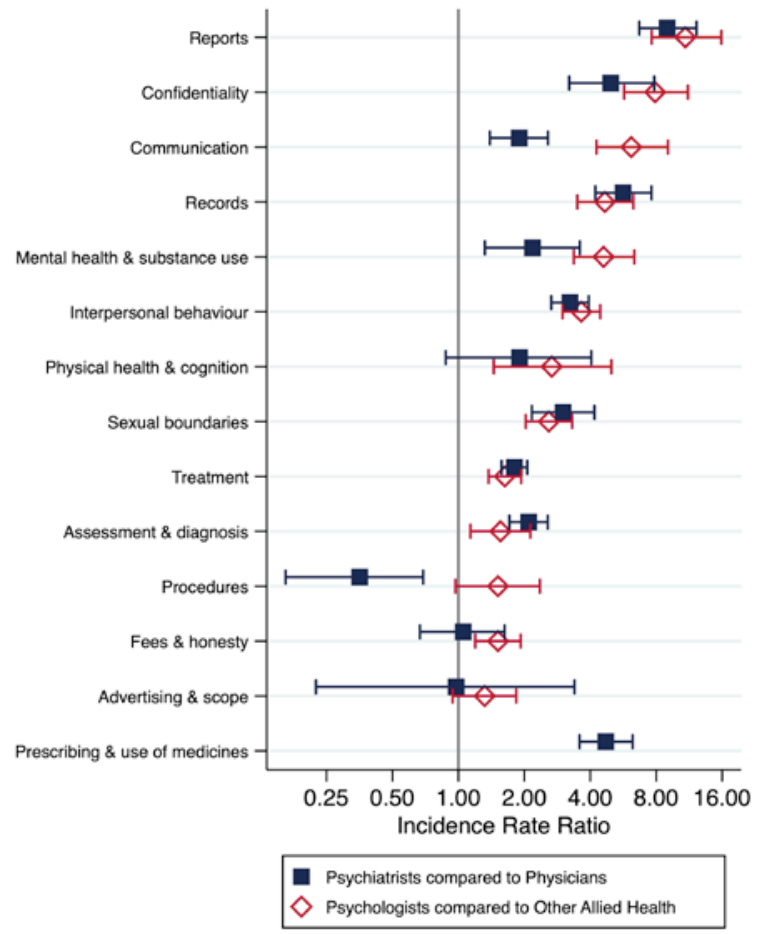

Figure 1 Incidence rate ratio of complaint issues for mental health practitioners compared with physical health practitioners (excludes complaints coded as 'health-other', 'conduct-other' and 'performance-other'. Psychologists compared with other allied health is not shown for 'prescribing and use of medicines' because such activities are outside these practitioners' scope of practise.

analysis sought to analyse predictors of complaints within this group (table 3).

Older mental health practitioners had a higher risk of complaints than their younger peers, after adjusting for sex and practice location. For both psychiatrists and psychologists, complaint risk increased steadily by age band, with practitioners aged $\geq 65$ years having around twice the risk of complaint compared with those aged 36-45 years (psychiatrists: IRR 2.37, 95\% CI 1.95 to 2.89; psychologists: IRR $1.78,95 \%$ CI 1.47 to 2.14 ).

Male psychiatrists and psychologists had higher complaint rates than their female peers (psychiatrists: IRR 1.61, 95\% CI 1.39 to 1.85; psychologists: IRR 1.85, $95 \%$ CI 1.65 to 2.07 ). There was no significant difference in psychiatrists' complaint risk based on their practice location, but psychologists practising in regional or rural areas had a $31 \%$ higher rate of complaint than those in metropolitan areas (IRR 1.31, 95\% CI 1.14 to 1.50 ).

A sensitivity analysis confined to complaints that resulted in regulatory action (such as the imposition of conditions) showed even larger risks among older mental health practitioners. Psychiatrists aged $\geq 65$ years were at almost eight times higher risk of being subject to a complaint that resulted in regulatory action, compared with those aged 36-45years (IRR 7.79, 95\% CI 3.31 to 18.33). For psychologists aged $\geq 65$ years, the risk was 
Table 3 Multivariate predictors of complaints about psychiatrists and psychologists by regulatory outcome

\begin{tabular}{|c|c|c|c|c|}
\hline & \multicolumn{2}{|l|}{ All complaints } & \multicolumn{2}{|c|}{ Complaints leading to regulatory action } \\
\hline & Psychiatrists & Psychologists & Psychiatrists & Psychologists \\
\hline & \multicolumn{4}{|c|}{ Adjusted IRR $(95 \% \mathrm{Cl})^{*}$} \\
\hline$\leq 35$ & $0.24(0.14$ to 0.44$)$ & 0.51 (0.43 to 0.60$)$ & NA & $0.43(0.26$ to 0.70$)$ \\
\hline $36-45$ & 1.00 & 1.00 & 1.00 & 1.00 \\
\hline $56-65$ & 1.71 (1.41 to 2.06$)$ & 1.64 (1.42 to 1.91$)$ & 4.28 (1.85 to 9.90$)$ & $2.18(1.48$ to 3.21$)$ \\
\hline$>65$ & 2.37 (1.95 to 2.89$)$ & 1.78 (1.47 to 2.14$)$ & 7.79 (3.31 to 18.33$)$ & 2.70 (1.69 to 4.33$)$ \\
\hline \multicolumn{5}{|l|}{ Sex } \\
\hline Female & 1.00 & 1.00 & 1.00 & 1.00 \\
\hline Male & 1.61 (1.39 to 1.85$)$ & 1.85 (1.65 to 2.07$)$ & 1.24 (0.71 to 2.19$)$ & 2.96 (2.23 to 3.91$)$ \\
\hline
\end{tabular}

*Analysis accounts for period of registration and an estimate of clinical hours worked by practitioners of the same age, sex and profession/ specialty.

IRR, incidence rate ratio.

almost three times greater (IRR $2.70,95 \%$ CI 1.69 to 4.33).

\section{DISCUSSION}

\section{Principal findings}

This analysis of nearly 8000 complaints lodged with regulators over a 6-year period identified important differences in the complaint profile of psychiatrists and psychologists, compared with physicians and other allied health practitioners, respectively. Mental health practitioners had a complaint rate that was more than twice that of physical health practitioners. Their risk of complaints was especially high in relation to reports they wrote, records, confidentiality, interpersonal behaviour and sexual boundary breaches. Consistent with previous studies, the risk was increased among mental health practitioners who were men and older.

\section{Strengths and weaknesses}

This research extends the existing evidence base in three new directions. First, we examined complaints about all registered mental health practitioners in a national jurisdiction over a multiyear period. Second, the availability of high-quality data facilitated more sophisticated identification and analysis of risk clusters than any previous study of complaints about mental health practitioners. In particular, the detailed data on practitioners' demographic characteristics and complaints lodged allowed us to disaggregate complaint rates while accounting for the period of registration and estimated clinical hours worked. Third, our study covered a broader set of complaint types than most previous studies. Previous studies regarding patterns of concern among psychiatrists and psychologists have often focused on sexual misconduct ${ }^{727}$ or on complaints that led to sanctions. ${ }^{12451227}$

Our study has several limitations. First, this study used retrospective observational data, which limits our ability to extrapolate findings into policy and practice recommendations. Second, we used routinely collected administrative data which limited the breadth and depth of information available to us. For example, we were unable to measure some important practitioner-level variables such as whether the psychiatrists and psychologists in our study were working in public or private practice, or the complexity of their caseload. Our findings may also have been confounded by patient-level variables which we were unable to measure, such as the age, health status and socioeconomic background of patients. In addition, health regulators coded the concerns raised by complaints when they were received, not when the complaint process ended. Therefore, this coding does not reflect new information uncovered during any subsequent investigation or information included in the text of the complaints themselves. Finally, we note that the relationship between complaints and quality care is imperfect: a lack of complaints is no guarantee that a practitioner is providing high-quality care ${ }^{192829}$ and some complaints occur in the absence of unacceptable risks or preventable harm. People using mental health services may face multiple barriers to making a complaint, including the impacts of their illness on autonomy and communication, fear of retribution or compromised future care, the accessibility of complaint mechanisms and the impact of stigma on their perceived credibility. In addition, we only included complaints to regulators, thus missing complaints made directly to the practitioner, their employer, other health 
complaints entities or other agencies. Conversely, some complaints may arise in the absence of any substandard conduct or performance by the practitioner. For example, some complaints may occur when there is a poor outcome despite an acceptable standard of care, when the illness itself results in the patient feeling that a wrong has occurred (eg, a patient may hold a delusional belief about the nature or purpose of treatment), or the patient may have been seeking secondary gain from a particular assessment outcome. Our data do not permit estimation of how many complaints were unfounded, as a decision to take no further regulatory action is not synonymous with a complaint being unfounded. Nevertheless, we note that there is mounting evidence that, at the population level, the incidence of complaints is a meaningful marker of lower-quality care. ${ }^{30-32}$

\section{The meaning of the study \\ Reports and records}

We found that mental health practitioners have over four times the risk of being subject to a complaint about reports or records compared with physical health practitioners. Reports by mental health practitioners can have significant impacts on the interests of individuals in areas such as child protection, insurance claims and civil, criminal or family law proceedings. ${ }^{1516}$ It seems plausible that older, more experienced practitioners are more often called on to do this kind of high-risk report writing for courts, which may contribute to their higher risk of complaint.

\section{Confidentiality}

Psychiatrists had five times the risk of being subject to a complaint about a breach of confidentiality compared with physicians, and for psychologists, the risk was nearly eight times higher than for other allied health practitioners. This may reflect the increased frequency with which mental health practitioners discuss the care of a patient with others, such as where the practitioner is concerned about the safety of the patient or others, or believes that a patient lacks the capacity to make decisions for themselves. This finding may also reflect failures by practitioners to explain the limits of confidentiality in a way that patients and family members can clearly understand. ${ }^{33}$ Finally, patients may be particularly sensitive to actual or perceived breaches of confidentiality when the information pertains to their psychological, as opposed to physical, health.

\section{Interpersonal behaviour}

Mental health practitioners had more than three times the risk of complaints about interpersonal behaviour, such as disrespect, discrimination, threats, or bullying, compared with physical health practitioners. The reason for this is unclear. However, contributing factors may include the intimate nature of information discussed during mental health consultations, the loss of autonomy involved in receiving involuntary treatment ${ }^{35}$ or experiencing significant mental illness, and the power dynamics at play-given the vulnerability and disadvantage of many users of mental health services. Many of these factors are reflected in submissions to the Royal Commission into Victoria's Mental Health System. ${ }^{36}$

\section{Boundaries}

In our study, mental health practitioners had three times the risk of complaint regarding sexual boundary breaches compared with physical health practitioners. High rates of concern about sexual misconduct by psychiatrists and psychologists are a consistent finding in previous studies of complaints, ${ }^{11}$ regulatory actions ${ }^{610} 12$ and self-reported behaviour. ${ }^{737}$ Compared with comparator professions in this study, the day-to-day practice of mental health practitioners more often involves being alone with patients behind closed doors, discussing more personally-intimate information, for longer periods of time. The power imbalance may be further intensified by mental health patients' emotional, cognitive or legal vulnerabilities.

\section{Communication}

Communication features as another area of risk, particularly for psychologists. This is perhaps explained by the nature of psychological consultations, in which verbal communication is the predominant means by which patients are both diagnosed and treated (even more so than psychiatric consultations, where there may be more of a focus on pharmacological treatment and monitoring of physical health). ${ }^{38}$

\section{Prescribing}

Psychiatrists were at increased risk of complaints regarding the prescribing of medicines. One possible explanation for this finding is that, compared with physicians, psychiatrists more commonly prescribe medications with potential for abuse or addiction (such as benzodiazepines) and/or troubling side effects. ${ }^{39}$ They are also more likely to prescribe medications to patients who may not have had the opportunity to exercise free and informed choice about their treatment.

\section{Mental health of practitioner}

Although concerns about the mental health of the practitioner were rare, accounting for $<5 \%$ of complaints, mental health practitioners had more than twice the risk of being subject to a notification about their own mental health compared with physical health practitioners. Previous studies have shown worrying levels of burnout and poor mental health among psychiatrists. ${ }^{4-42}$ This is an important finding, both because of its implications for the well-being of psychiatrists and because poor mental health can adversely affect patient care. ${ }^{43-45}$ We note that some of this increased risk may also reflect a heightened awareness of mental health issues among mental health practitioners.

Male practitioners

We found that, even after adjusting for age, clinical hours worked, and practice location, male mental health 
practitioners were over $50 \%$ more likely to attract a complaint compared with their female peers. Previous studies have also found that the risk of complaints or disciplinary action against psychiatrists and psychologists is higher if practitioners are men. ${ }^{1251718}$ This finding may reflect differences in communication style between male and female practitioners, as female doctors have been shown to engage in longer consultations and to use more patient-centred communication than their male colleagues, in general. ${ }^{46}$

\section{Older practitioners}

Our study showed that older mental health practitioners were more likely to attract complaints, particularly complaints that resulted in misconduct findings. Previous studies have also found that the risk of complaints or disciplinary action against psychiatrists and psychologists is higher if practitioners are middle-aged or older. ${ }^{517}$ One possible explanation is that older practitioners, being typically more experienced, are more exposed to areas of mental health at higher risk for complaints, such as medicolegal reports for courts or complex cases. Alternatively, the elevated risk may reflect more current knowledge and stronger professional standards among younger practitioners, who might also have a greater awareness of current social norms (eg, attitudes towards gender/sex, sexuality, race/ethnicity and so on).

\section{Regional psychologists}

We found that regional psychologists were at a $30 \%$ increased risk of complaint compared with regional other allied health practitioners. This finding may reflect the challenges of providing treatment in a close-knit, smaller community. Compared with psychiatrists, who may fly-in and fly-out, psychologists in Australia are more likely to reside in the community, meaning issues of confidentiality and work-life boundaries may be more difficult to manage. In addition, psychologists in small regional and rural towns may face workforce shortages ${ }^{47}$ and limited access to high-quality professional development, peer review and supervision, risking a drift in professional competence and weaker oversight.

\section{Implications for clinicians and policy-makers}

A pressing challenge in mental healthcare is the occurrence of patient harm and distress as a result of interactions with the health system. Complaints provide a valuable source of information on patient harm and experience. Australia's national regulatory scheme, which oversees practitioners from 15 health professions and collects detailed information on them, including their complaints experiences, provides a valuable opportunity to identify risk factors for complaints among psychiatrists and psychologists.

Our findings bolster calls to better understand the patient perspective within mental health practice, including identifying and sharing lessons from previous complaints. They also raise questions about whether more should be done to develop skills beyond diagnosis and treatment-including professional ethics and written communication-during training and ongoing professional development. Finally, our findings lend weight to efforts to support the mental health of mental health practitioners themselves and to ensure the fitness to practise of mental health practitioners as they age.

Further research should explore whether addressing these risk factors through changes to training and continuing education curricula, professional culture and practice, and practitioner health initiatives may reduce the risk of complaints about mental health practitioners and improve patient care.

\section{Author affiliations}

${ }^{1}$ Mental and Addiction Health, Alfred Health, Prahran, Victoria, Australia

${ }^{2}$ University of Melbourne School of Population and Global Health, Parkville, Victoria, Australia

${ }^{3}$ University of Wollongong Illawarra Health and Medical Research Institute, Wollongong, New South Wales, Australia

${ }^{4}$ University of Wollongong School of Psychology, Wollongong, New South Wales, Australia

${ }^{5}$ Brain and Mind Centre, University of Sydney, Camperdown, New South Wales, Australia

${ }^{6}$ Sydney Local Health District, Sydney, New South Wales, Australia

${ }^{7}$ Stanford University School of Medicine, Stanford, California, USA

${ }^{8}$ Stanford Law School, Stanford, California, USA

Twitter Benjamin G Veness @venessb, Holly Tibble @hollytibble and Marie M Bismark@mbismark

Acknowledgements The authors acknowledge the assistance of Malcolm Hopwood, Jo Katsoris, Martin Roberts, Paul Shinkfield and Richard Harvey in reviewing an early draft of the manuscript, and Yamna Taouk for her careful examination of our statistical analyses.

Contributors BV, MB, HT, DS and MS conceived the study, interpreted results, and contributed to the writing of the manuscript. HT and MS analysed the data. $\mathrm{LN}, \mathrm{BG}$ and JM contributed to the interpretation of results and the writing of the manuscript.

Funding This work was supported by the National Health and Medical Research Council and the Australian Health Practitioner Regulation Agency through a Partnership Grant awarded to the University of Melbourne, and the Royal Australian and New Zealand College of Psychiatrists through a New Investigator Grant awarded to Benjamin Veness. Matthew Spittal is a recipient of an Australian Research Council Future Fellowship (project number FT180100075) funded by the Australian Government.

Competing interests BV and MB are trainees with the Royal Australian and New Zealand College of Psychiatrists, $L N$ is a consultant psychiatrist, and BG formerly chaired the Psychology Board of Australia.

Patient consent for publication Not required.

Ethics approval The University of Melbourne's Health Sciences Human Ethics Sub-Committee approved the study (Ethics Application 1543670.5).

Provenance and peer review Not commissioned; externally peer reviewed.

Data availability statement Data may be obtained from a third party and are not publicly available.

Open access This is an open access article distributed in accordance with the Creative Commons Attribution Non Commercial (CC BY-NC 4.0) license, which permits others to distribute, remix, adapt, build upon this work non-commercially, and license their derivative works on different terms, provided the original work is properly cited, appropriate credit is given, any changes made indicated, and the use is non-commercial. See: http://creativecommons.org/licenses/by-nc/4.0/.

ORCID iDs

Benjamin G Veness http://orcid.org/0000-0002-8849-2892 
Holly Tibble http://orcid.org/0000-0001-7169-4087

Brin FS Grenyer https://orcid.org/0000-0003-1501-4336

Matthew J Spittal https://orcid.org/0000-0002-2841-1536

Marie M Bismark https://orcid.org/0000-0003-0114-2388

\section{REFERENCES}

1 Elkin KJ, Spittal MJ, Elkin DJ, et al. Doctors disciplined for professional misconduct in Australia and New Zealand, 2000-2009. Med J Aust 2011;194:452-6.

2 Khaliq AA, Dimassi H, Huang C-Y, et al. Disciplinary action against physicians: who is likely to get disciplined? Am J Med 2005;118:773-7.

3 Cardarelli R, Licciardone JC, Ramirez G. Predicting risk for disciplinary action by a state Medical board. Tex Med 2004;100:84-90.

4 Alam A, Klemensberg J, Griesman J, et al. The characteristics of physicians disciplined by professional colleges in Canada. Open Med 2011;5:e166.

5 Kohatsu ND, Gould D, Ross LK, et al. Characteristics associated with physician discipline: a case-control study. Arch Intern Med 2004;164:653-8.

6 Kirkland K, Kirkland KL, Reaves RP. On the professional use of disciplinary data. Prof Psychol 2004;35:179-84.

7 Garrett T, Davis J. Patients as victims: sexual abuse in psychotherapy and counselling. In: Jehu D, ed. Epidemiology in the UK. Chichester, England: Wiley, 1994: 37-57.

8 Wincze JP, Richards J, Parsons J, et al. A comparative survey of therapist sexual misconduct between an American state and an Australian state. Prof Psychol 1996;27:289-94.

9 Nortje N, Hoffmann WA. Ethical misconduct by registered psychologists in South Africa during the period 2007-2013. S Afr J Psychol 2015;45:260-70.

10 Association of State and Provincial Psychology Boards. ASPPB disciplinary data system: historical discipline report (reported disciplinary actions for psychologists: $1974-2016), 2014$. Available: http://c.ymcdn.com/sites/www.asppb.net/resource/resmgr/dds/ DDS_Historical_Report_2016.pdf [Accessed 23 Oct 2017].

11 Scherrer R, Louw DA, Möller AT. Ethical complaints and disciplinary action against South African psychologists. S Afr J Psychol 2002;32:54-64.

12 Morrison J, Morrison T. Psychiatrists disciplined by a state Medical board. Am J Psychiatry 2001;158:474-8.

13 Hall JE, Hare-Mustin RT. Sanctions and the diversity of ethical complaints against psychologists. Am Psychol 1983;38:714-29.

14 Surgenor LJ, Diesfeld K. Outcomes of notifications against psychologists in the New Zealand health regulation context 20042015. J Law Med 2018;25:800-13.

15 Bow JN, Gottlieb MC, Siegel JC, et al. Licensing board complaints in child custody practice. J Forensic Psychol Pract 2010;10:403-18.

16 Bow JN, Martindale DA. Developing and managing a child custody practice. J Forensic Psychol Pract 2009;9:127-37.

17 Grenyer BFS, Lewis KL. Prevalence, prediction, and prevention of psychologist misconduct. Aust Psychol 2012;47:68-76.

18 Bismark MM, Spittal MJ, Gurrin LC, et al. Identification of doctors at risk of recurrent complaints: a national study of healthcare complaints in Australia. BMJ Qual Saf 2013;22:532-40.

19 Bismark MMet al. Relationship between complaints and quality of care in New Zealand: a descriptive analysis of complainants and non-complainants following adverse events. BMJ Qual Saf 2006;15:17-22.

20 Catron TF, Guillamondegui OD, Karrass J, et al. Patient complaints and adverse surgical outcomes. Am J Med Qual 2016;31:415-22.

21 Cooper WO, Spain DA, Guillamondegui O, et al. Association of coworker reports about unprofessional behavior by surgeons with surgical complications in their patients. JAMA Surg 2019;154:828.

22 Reader TW, Gillespie A, Roberts J. Patient complaints in healthcare systems: a systematic review and coding taxonomy. BMJ Qual Saf 2014;23:678-89.
23 Gillespie A, Reader TW. The healthcare complaints analysis tool: development and reliability testing of a method for service monitoring and organisational learning. BMJ Qual Saf 2016;25:937-46.

24 Pichert JW, Hickson G, Moore I. Using patient complaints to promote patient safety. advances in patient safety: new directions and alternative approaches ( $v o l$ 2: culture and redesign. Agency for Healthcare Research and Quality (US), 2008.

25 Department of Health. National health workforce dataset Canberra: Australian government department of health, 2015. Available: http:// data.hwa.gov.au/datasets.html\#part-1 [Accessed 26 Mar 2018]

26 Spittal MJ, Studdert DM, Paterson R, et al. Outcomes of notifications to health practitioner boards: a retrospective cohort study. BMC Med 2016;14:198.

27 Dehlendorf CE, Wolfe SM. Physicians disciplined for sex-related offenses. JAMA 1998;279:1883-8.

28 Pope KS, Bajt TR. When laws and values conflict: a dilemma for psychologists. Am Psychol 1988;43:828-9.

29 Levtzion-Korach O, Frankel A, Alcalai $\mathrm{H}$, et al. Integrating incident data from five reporting systems to assess patient safety: making sense of the elephant. Jt Comm J Qual Patient Saf 2010;36:402-18.

30 Bismark MM, Brennan TA, Paterson RJ, et al. Relationship between complaints and quality of care in New Zealand: a descriptive analysis of complainants and non-complainants following adverse events. Qual Saf Health Care 2006;15:17-22.

31 Hickson GB, Federspiel CF, Pichert JW, et al. Patient complaints and malpractice risk. JAMA 2002;287:2951-7.

32 Murff HJ, France DJ, Blackford J, et al. Relationship between patient complaints and surgical complications. Qual Saf Health Care 2006;15:13-16.

33 Fisher MA. The ethics of conditional confidentiality: a practice model for mental health professionals. Oxford University Press, 2013.

34 Petrik ML, Billera M, Kaplan Y, et al. Balancing patient care and confidentiality: considerations in obtaining collateral information. $J$ Psychiatr Pract 2015;21:220-4.

35 Vine R. Decision-making by psychiatrists about involuntary detention. Involuntary detention and therapeutic jurisprudence. Routledge, 2018: 113-32.

36 The State Government of Victoria. Terms of Reference for the Royal Commission into Victoria's Mental Health System, 2019. Available: https://s3.ap-southeast-2.amazonaws.com/hdp.au.prod.app.vicengage.files/4515/5081/4577/RCMH_ToR_Consultation_Summary. pdf

37 Hook J, Devereux D. Sexual boundary violations: victims, perpetrators and risk reduction. BJPsych Adv 2018;24:374-83.

38 McCabe R, Healey PGT. Miscommunication in doctor-patient communication. Top Cogn Sci 2018;10:409-24.

39 Lev R, Lee O, Petro S, et al. Who is prescribing controlled medications to patients who die of prescription drug abuse? Am J Emerg Med 2016;34:30-5.

40 Kumar S. Burnout in psychiatrists. World Psychiatry 2007;6:186-9.

41 Kumar S, Fischer J, Robinson E, et al. Burnout and job satisfaction in New Zealand psychiatrists: a national study. Int J Soc Psychiatry 2007:53:306-16.

42 Firth-Cozens J. Improving the health of psychiatrists. Advances in Psychiatric Treatment 2007;13:161-8.

43 Fahrenkopf AM, Sectish TC, Barger LK, et al. Rates of medication errors among depressed and burnt out residents: prospective cohort study. BMJ 2008;336:488-91.

44 Brown SD, Goske MJ, Johnson CM. Beyond substance abuse: stress, burnout, and depression as causes of physician impairment and disruptive behavior. J Am Coll Radiol 2009;6:479-85.

45 Panagioti M, Geraghty K, Johnson J, et al. Association between physician burnout and patient safety, professionalism, and patient satisfaction: a systematic review and meta-analysis. JAMA Intern Med 2018;178:1317-31.

46 Roter DL, Hall JA, Aoki Y. Physician gender effects in medical communication: a meta-analytic review. JAMA 2002;288:756-64.

47 Cosgrave C, Hussain R, Maple M. Factors impacting on retention amongst community mental health clinicians working in rural Australia: a literature review. Advances in Mental Health 2015;13:58-71. 